\title{
Influence of the temperature at the Black Sea ctenophores-aliens bioluminescence characteristics
}

\author{
Mashukova Olga*, Tokarev Yuriy \\ Department of the Biophysical Ecology, Kovalevsky Institute of Biology of the Southern Seas (IBSS), National Academy of Sci- \\ ences of Ukraine, Sevastopol, Ukraine \\ Email: ${ }^{\text {olgamashukova@yandex.ru }}$
}

Received 14 February 2012; revised 20 March 2012; accepted 1 April 2012

\begin{abstract}
Successful invasion of Mnemiopsis leidyi A. Agassiz, 1865 and Beroe ovata Mayer, 1912 into the Black Sea and their important role in this region pelagic ecosystem is stipulated mainly by the considerable eurythermy of these species. Many ecological-physiological characteristics of ctenophores-aliens are studied quite well. However, bioluminescence, one of the most important elements of the ctenophores ecology and the bioluminescence reaction temperature optimum for these individuals under different environment temperatures were not studied sufficiently. Therefore our researches in this scientific field are significant and conceptually novel for ctenophores ecology study. Experimental investigations were carried out in the period of 2008-2009 in the IBSS. Uni-sized $(40 \mathrm{~mm})$ ctenophores were collected in the Sevastopol coastal zone and divided in several groups, contained under different temperatures: from $10^{\circ} \mathrm{C} \pm 1^{\circ} \mathrm{C}$ to $30^{\circ} \mathrm{C} \pm$ $1^{\circ} \mathrm{C}$. Ctenophore bioluminescence was investigated under chemical and mechanical stimulation. M. leidyi light emission maximal amplitude (1432.94 $\pm 71.64 \times$ $10^{8}$ quantum $\cdot \mathrm{s}^{-1} \cdot \mathrm{cm}^{-2}$ ) with duration of $3.54 \pm 0.15 \mathrm{~s}$ is fixed under the temperature of $26^{\circ} \mathrm{C} \pm 1^{\circ} \mathrm{C}$. Temperature increase up to $30^{\circ} \mathrm{C} \pm 1^{\circ} \mathrm{C}$ led to the 4 times decrease of the bioluminescence intensity. Under temperature decrease up to $10^{\circ} \mathrm{C} \pm 1^{\circ} \mathrm{C}$ this parameter decreased 20 times $(p<0.05)$. Bioluminescence emission intensity characteristics of $B$. ovata achieved maximal values under the temperature of $22^{\circ} \mathrm{C} \pm 1^{\circ} \mathrm{C}$ $\left(1150.12 \pm 57.51 \times 10^{8}\right.$ quantum $\left.\cdot \mathrm{s}^{-1} \cdot \mathrm{cm}^{-2}\right)$ with duration of $3.03 \pm 0.15 \mathrm{~s}$. The luminescence intensity decreased under the temperature increase to $30^{\circ} \mathrm{C} \pm 1^{\circ} \mathrm{C}$ more than 20 times. Temperature decrease to the values of $10^{\circ} \mathrm{C} \pm 1^{\circ} \mathrm{C}$ impacted decreasing the amplitude of bioluminescence up to the minimal $-4.92 \pm$ $0.22 \times 10^{8}$ quantum $\cdot \mathrm{s}^{-1} \cdot \mathrm{cm}^{-2}$. The data obtained testify that characteristics of the ctenophores biolumi-
\end{abstract}

${ }^{*}$ Corresponding author. nes- cence can be conditioned not only by the modification the environment temperature but by the variability of their physiological condition.

Keywords: Bioluminescence; Beroe ovata; Mnemiopsis leidyi; Black Sea; Temperature

\section{INTRODUCTION}

Ctenophores Mnemiopsis leidyi A. Agassiz, 1865 and Beroe ovata Mayer, 1912, invaded the Black Sea in 80 90-ties of the past century, effected considerably on the Black Sea ecosystem. Ctenophore M. leidyi, which invaded the Black Sea aquatorium with the ballast waters in the end of 80-ties, beginning of 90-ties, caused the mass growth of abundance [1]. This alien-species affected the feed mezozooplankton biomass, having undermined feed base of the plankton-eating fish - the base of the Black Sea market, pelagic fishes: anchovy, sprat, scad [2] considerably, together with another factors (climatic changes, in particular). Thus, mass growth of $M$. leidyi caused increase of the fish larvae share with the empty stomachs, which led to the food fish population decrease and their catches reduction more than 5 times by 1991 [3], resulted in economy loses because of the anchovy stocks decrease, evaluated in $240 \mathrm{mln}$ dollars per year [4].

Another ctenophore B. ovata, which eats mnemiopsis, invaded the Black Sea at the end of 90-ties. Mnemiopsis abundance had decreased by 2000-2001, because $B$. ovata ate $80 \%$ of this ctenophore day biomass and that influenced the feed base of plankton-eating fish and their larvae state improvement [3].

Many ecological and physiological parameters of ctenophores $M$. leidyi and B. ovata are well-studied because they play a very important ecological role in the Black Sea ecosystem $[5,6]$. But bioluminescence, one of the most considerable elements of the ctenophore ecology, has not been yet investigated enough.

Besides, environment temperature conditions are the 
most important for ctenophore vitality regulation together with other environment abiotic factors (light, salinity). Thus, ctenophore M. leidyi, having considerable eurythermy, can bear temperature changes from $1.3^{\circ} \mathrm{C}$ up to $28.8^{\circ} \mathrm{C}$ [7]. Ability of $M$. leidyi to keep high exchange intensity under the temperature, inherent to the surface horizons of the Black Sea in the summer time, was of importance for the mass development of this species [8] and following introduction and distribution of B. ovata in the Black Sea was also stipulated by the favorable environment temperature conditions [9] for this species.

Vertical distribution of $93 \%$ of the alien ctenophore biomass takes place higher the thermocline and only $11 \%$ is lover it $[10,11]$. Statistically considerable exceeding of $M$. leidyi abundance and biomass in the coastal more warm part of the Black Sea was revealed in comparison with deep-water one [10]. At last, B. ovata population as well as $M$. leidyi one remains in the coastal heatedup waters-in that biotope, where their preys live [11].

Study of different temperature conditions effect on the alien-ctenophore light-emission parameters and determination of the bioluminescence temperature optimum was the aim of our work, taking into consideration the importance of temperature for the ctenophore vital activity.

\section{MATERIALS AND METHODS}

\subsection{Study Area}

Sevastopol Bay aquatorium is characterized by small depths, temperature, which achieves $25^{\circ} \mathrm{C} \pm 2^{\circ} \mathrm{C}$ in summer time, and $14^{\circ} \mathrm{C} \pm 2^{\circ} \mathrm{C}$ in autumn, and salinity diapason from $14 \%$ o to $18 \%$. Experimental investigations were conducted in the Biophysical ecology department of IBSS of NAS of Ukraine in the period from June till October of 2008-2009.

We were studying the stations of Sevastopol Bay and also 2-mile zone from coast as a permanent dwelling environment of ctenophores during out researches (Figure 1). Ctenophores were collected for experiments at

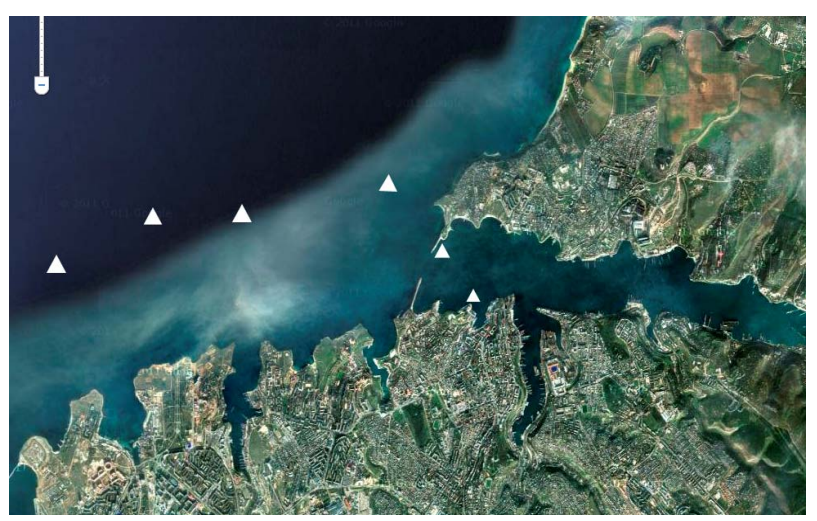

Figure 1. The scheme of stations with ctenophores collection in the Sevastopol coastal zone. the 10 stations of this region by Judy net vertical catches. The depth of water catch was 0 - $50 \mathrm{~m}$. Ctenophore with sizes of 35 - $40 \mathrm{~mm}$ (oral-aboral length for M. leidyi and total for $B$. ovata) were gathered from the sea. Notdamaged samples without content in the gastrovaskular cavity were chosen for experiments.

Ctenophores were divided in the laboratory into 5 groups and contained in different temperature conditions: 1) $10^{\circ} \mathrm{C} \pm 1{ }^{\circ} \mathrm{C}$; 2) $16^{\circ} \mathrm{C} \pm 1{ }^{\circ} \mathrm{C}$; 3) $22^{\circ} \mathrm{C} \pm 1^{\circ} \mathrm{C}$; 4) $26^{\circ} \mathrm{C} \pm 1{ }^{\circ} \mathrm{C}$; and 5) $30^{\circ} \mathrm{C} \pm 1^{\circ} \mathrm{C}$. Ctenophores were in the filtered (diameter of the filter membrane pores was of $35 \mu \mathrm{m}$ ) water under the given temperature in the jars with the volume of 5l. Sampling of the uni-sized ctenophore made 35 - 40 species in each group.

\subsection{The Methods of the Ctenophores Bioluminescence Registration}

Experiments on ctenophore bioluminescence registration by the laboratory complex-luminescope "Light" [12] were conducted after the adaptive period, (2 hours). The laboratory complex included a high-voltage power device (VS-22), luminescope, consisting of light radiation receiver (FEU-71), dark chamber for an object and the digital registering device. Special cuvette for mechanical, chemical and electrical stimulation of plankton organisms, in which experimental organisms were placed, was set into the luminescope dark chamber. Registration of ctenophores bioluminescence characteristics were measured at full darkness. Biophysical characteristics of the ctenophore light emission were investigated under mechanical and chemical stimulation in our experiments.

Mechanical stimulation method, the most adequate to the natural stimuli [13], consists of creating the water stream in the jar with the bioluminescent by pumping electro-mechanical device [12]. Changes of the hydrophysical characteristics, arising with this, led to the ctenophore cell membrane deformation, induction of the action potential and, as a consequence, light emission. Method of the chemical stimulation was used for obtaining the information about ctenophore maximal bioluminescent potential. $3 \mathrm{~cm}^{3}$ of $96 \%$ ethyl alcohol, chosen as a chemical stimulus was injected into cuvette with the syringe [12].

The main parameters: amplitude, energy and bioluminescence duration of the alien-ctenophores under the different temperature conditions were compared.

\section{RESULTS AND DISCUSSION}

\subsection{Variability of the Ctenophore Mnemiopsis leidyi Bioluminescence Characteristics under Different Temperature Conditions}

The investigations results have shown considerable changes 
of the M. leidyi bioluminescence intensity, connected with temperature changes (Figure 2). Thus, maximal indices of the ctenophore signals amplitude were observed under the temperature of $26^{\circ} \mathrm{C} \pm 1^{\circ} \mathrm{C}$ under chemical, as well as under mechanical stimulation.

Ctenophore light emission amplitude was 1.5 times higher, than under the mechanical one, making 1432.94 $\pm 71.64 \times 10^{8}$ quantum $\cdot \mathrm{s}^{-1} \cdot \mathrm{cm}^{-2}$ under the chemical stimulation. Ctenophore light emission amplitude decreased 4 times, making $322.34 \pm 16.1 \times 10^{8}$ quantum $\cdot \mathrm{s}^{-1} \cdot \mathrm{cm}^{-2}$ under the temperature increase up to $30^{\circ} \mathrm{C}$. Ctenophore bioluminescence amplitude decreased 2 times $(\mathrm{p}<0.05)$ comparing with optimum under the temperature decrease down to $22^{\circ} \mathrm{C}$. Further temperature decrease down to $10^{\circ} \mathrm{C} \pm 1^{\circ} \mathrm{C}$ leads to more considerable bioluminescence intensity change, up to its minimal values $17.32 \pm 0.83 \times$ $10^{8}$ under mechanical and $17.93 \pm 0.89 \times 10^{8}$ quantum $\cdot \mathrm{s}^{-1} \cdot \mathrm{cm}^{-2}$ under the chemical stimulation correspondingly.

Bioluminescence energy varies under the temperature change as well as amplitude according the investigations (Figure 3). Thus, ctenophore light emission energy achieves maximal indices under $26^{\circ} \mathrm{C}$, making $894.64 \pm$ $44.7 \times 10^{8}$ - under the chemical and $725.33 \pm 36.2 \times 10^{8}$ quantum $\cdot \mathrm{cm}^{-2}$ under the mechanical stimulation. Temperature increase up to $30^{\circ} \mathrm{C}$ leads to the sharp light emission energy reduction down to $265.15 \pm 13.25 \times 10^{8}$ quantum $\cdot \mathrm{cm}^{-2}$.

Light emission energy decreases 2 times $(\mathrm{p}<0.05)$ under the temperature of $22^{\circ} \mathrm{C}$. This tendency remains under the following temperatures decrease from 26 down to $16^{\circ} \mathrm{C}$. The ctenophore bioluminescence energy minimal values were registered under the temperature of $10^{\circ} \mathrm{C}$.

Temperature oscillations influenced the ctenophore signals duration change. Thus, minimal values were registered under the temperature decrease down to $10^{\circ} \mathrm{C}$ as

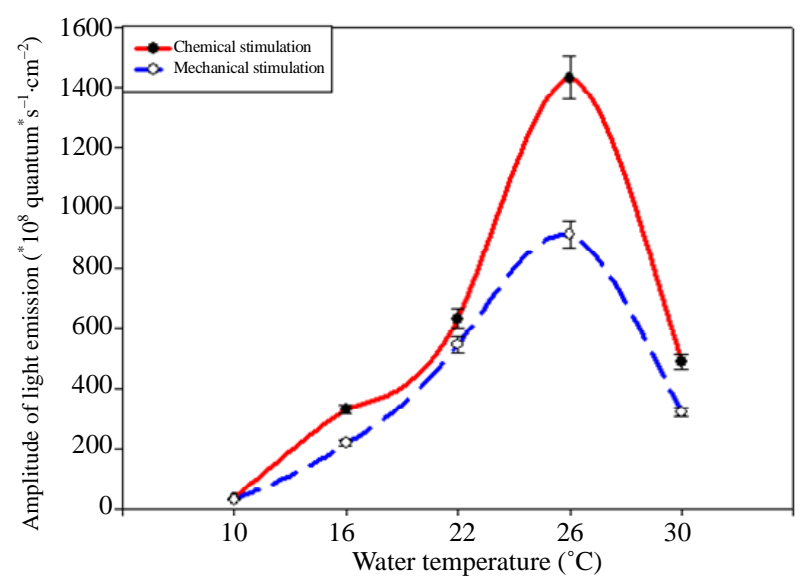

Figure 2. M. leidyi light emission amplitude depending on environment temperature. well as under its rise up to $30^{\circ} \mathrm{C}$, making 1.94 and $2.67 \mathrm{~s}$ correspondingly (Figure 4).

The most continuous signals were registered under the temperature of $26^{\circ} \mathrm{C}-3.54 \pm 0.15 \mathrm{~s}$, under the chemical stimulation especially.

\subsection{The Ctenophore Beroe ovata Bioluminescence Characteristics under Different Temperature Conditions}

Amplitude and light emission energy considerable changes, connected with the environment temperature change, were revealed in ctenophore B. ovata (Figures 5 and 6). Thus, $B$. ovata flashes amplitude had the maximal indices under the temperature of $22^{\circ} \mathrm{C} \pm 11^{\circ} \mathrm{C}$ regardless the type of stimulation (Figure 5), having achieved $1150 \pm 57.51 \times$ $10^{8}$ quantum $\cdot \mathrm{s}^{-1} \cdot \mathrm{cm}^{-2}$ under the mechanical and $822.03 \pm$ $41.10 \times 10^{8}$ quantum $\cdot \mathrm{s}^{-1} \cdot \mathrm{cm}^{-2}$ under the chemical stimulation correspondingly.

Ctenophore demonstrates lower light emission amplitude indices with the temperature rise up to $26^{\circ} \mathrm{C}$, but

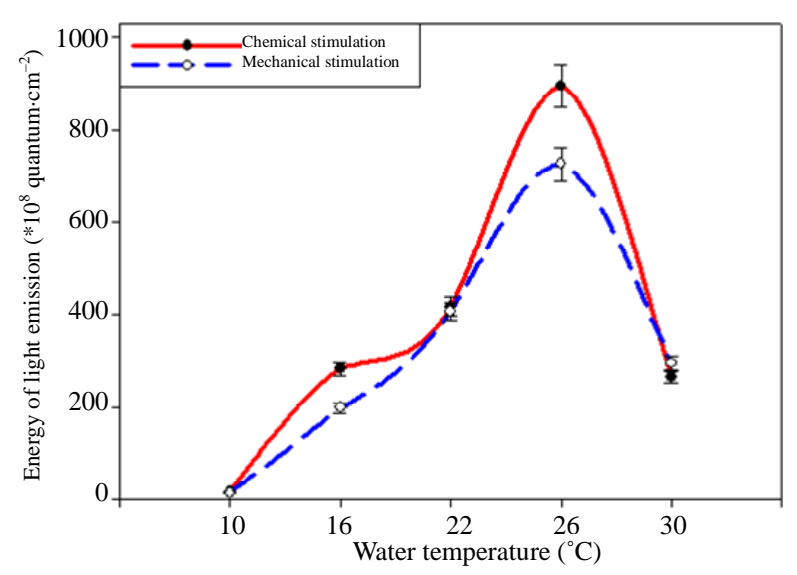

Figure 3. M. leidyi light emission energy depending on environment temperature.

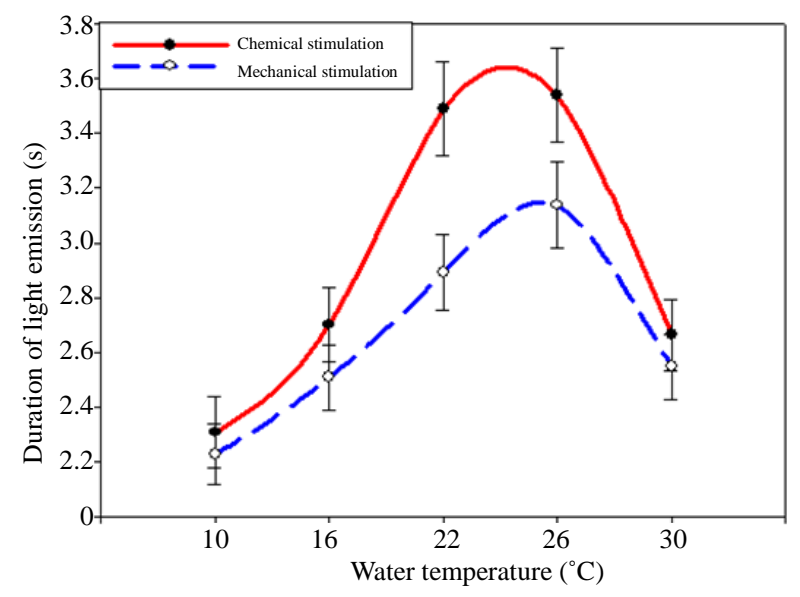

Figure 4. Dependence between $M$. leidyi light-emission duration and environment temperature. 


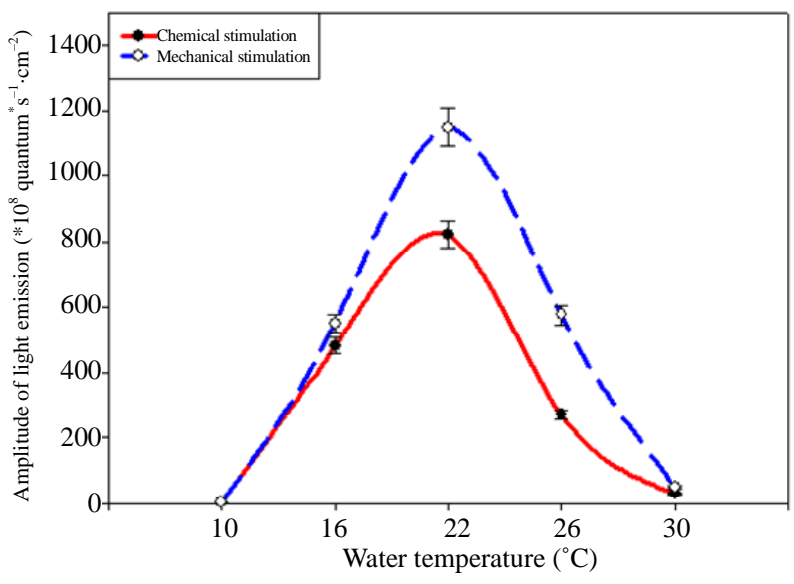

Figure 5. B. ovata light emission amplitude depending on environment temperature.

minimal indices of the light emission intensity are observed under the temperature of $30^{\circ} \mathrm{C}$, making $49.01 \pm$ $2.4 \times 10^{8}$ and $29.23 \pm 1.46 \times 10^{8}$ quantum $\cdot \mathrm{s}^{-1} \cdot \mathrm{cm}^{-2}$ under the mechanical and chemical stimulation correspondingly.

Temperature decrease down to $10^{\circ} \mathrm{C} \pm 1^{\circ} \mathrm{C}$ affects the ctenophore functional state negatively also. It is expressed by the weakening their moving activity and in lowering their luminescence amplitude indices: down to $3.42 \pm$ $0.16 \times 10^{8}$ quantum $\cdot \mathrm{s}^{-1} \cdot \mathrm{cm}^{-2}$ under the chemical stimulation and $4.92 \pm 0.22 \times 10^{8}$ quantum $\cdot \mathrm{s}^{-1} \cdot \mathrm{cm}^{-2}$ under the mechanical one.

The analogous situation is observed concerning $B$. ovata light emission energy change, which maximal indices are observed under the temperature of $22^{\circ} \mathrm{C}$ also, achieving $530.19 \pm 26.5 \times 10^{8}$ quantum $\mathrm{cm}^{-2}$ and minimal-under the temperature of $10^{\circ} \mathrm{C}$, making $2.95 \pm 0.12$ $\times 10^{8}$ quantum $\cdot \mathrm{cm}^{-2}$ (Figure 6).

Temperature increase up to $30^{\circ} \mathrm{C}$ affects energy light emission indices also negatively, making $14.73 \pm 0.73 \times$ $10^{8}$ quantum $\cdot \mathrm{cm}^{-2}$ only. Ctenophore signals duration varied considerably under the temperature change (Figure 7).

Thus, the shortest bioluminescent signals were being registered during the chemical stimulation under the temperature of $10^{\circ} \mathrm{C} 1.02 \pm 0.05 \mathrm{~s}$, and the most continuous during the mechanical stimulation under $22^{\circ} \mathrm{C}(3.03 \pm$ $0.15) \mathrm{s}$.

\subsection{The Bioluminescence of the Black Sea Ctenophores-aliens as the Physiological Adaptation of Them to the Environment Temperature}

Ctenophore bioluminescence characteristics changes, under the different temperature conditions, can be explained, we believe, from these organisms physiological adaptations to the environment temperature oscillations

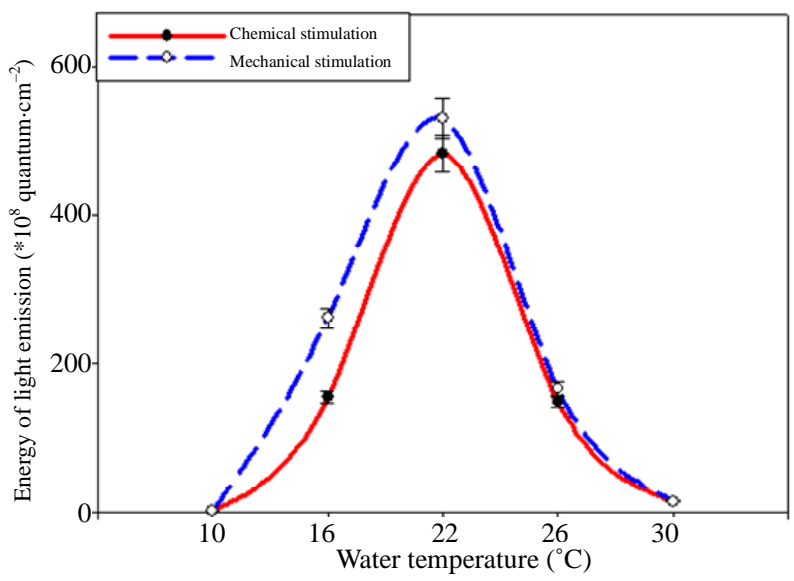

Figure 6. B. ovata light emission energy depending on environment temperature.

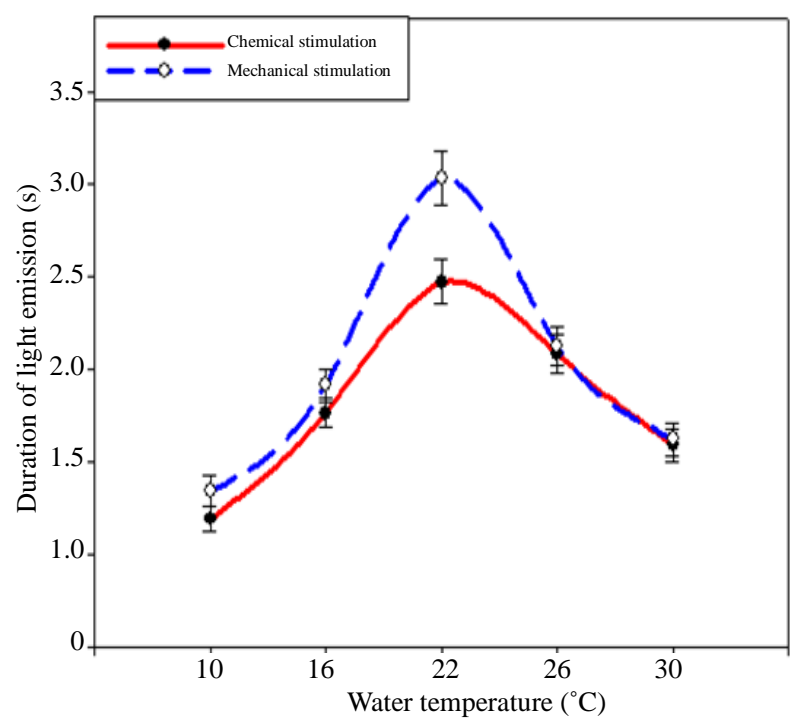

Figure 7. Dependence between $B$. ovata light emission duration and environment temperature.

point of view. Indeed, the most intensive $M$. leidyi luminescence is observed under the temperature of $26^{\circ} \mathrm{C} \pm$ $1^{\circ} \mathrm{C}$, and $B$. ovata - under $22^{\circ} \mathrm{C} \pm 1^{\circ} \mathrm{C}$, which are the most favorable for their functional state. Thus, according to the data of B. E. Anninsky with co-authors, M. leidyi [8] breeding peak is observed under the temperature of $24^{\circ} \mathrm{C}-26^{\circ} \mathrm{C}$ in August, and ctenophore B. ovata $[9,14]$ autumn quantity growth under the temperature $20^{\circ} \mathrm{C}$ $22^{\circ} \mathrm{C}$. With this, organisms are actively breeding and their metabolism level is considerably higher, than under lower temperatures.

Ctenophore $M$. leidyi and B. ovata bioluminescence amplitude decrease for several orders of magnitude under the temperature decrease down to $10^{\circ} \mathrm{C}$ can be explained by the fact, that ctenophore endures the fall of temperature badly and their populations abundance reduces in 
the late-autumn and in the winter period sharply [7,9].

Together with that, temperature rise up to $30^{\circ} \mathrm{C}$, affects the ctenophore state unfavorably. There are many literature materials, which testify to the fact, that ctenophore feels worse under the temperature rise: its motion activity gets broken, metabolism level reduces etc. $[8,14]$.

It is known that maximal activity of the enzyme-substrate complex, basic for the bioluminescence as a phenomena was registered under the temperature of $30^{\circ} \mathrm{C}$ in vivo $[15,16]$. Bioluminescence intensity maximum was registered in our laboratory experiments under other temperatures: under $26^{\circ} \mathrm{C}$ for $M$. leidyi and under $22^{\circ} \mathrm{C}$ for $B$. ovata, that underlines the circumstance, than amplitude, energy and temporal characteristics of any bioluminescent light emission, including the Black Sea ctenophores-aliens, depend on total environment conditions, determining physiological state of the organism as well as on luciferine-luciferase complexes reaction velocity.

\section{CONCLUSION}

Environment temperature affects considerably the amplitude-temporal characteristics of the Black Sea alienctenophore light emission. It was revealed, that bioluminescence reaction optimum for $M$. leidyi is achieved under the temperature of $26^{\circ} \mathrm{C} \pm 1^{\circ} \mathrm{C}$, and for $B$. ovataunder the temperature of $22^{\circ} \mathrm{C} \pm 1^{\circ} \mathrm{C}$, while its minimum for both ctenophore species was registered under the temperature of $10^{\circ} \mathrm{C} \pm 1^{\circ} \mathrm{C}$. It was shown, that variability of the alien-ctenophore bioluminescence parameters is stipulated by dependence between luciferine-luciferase complexes reaction velocity and environment temperature as well as by changes of the ctenophore functional state (metabolism and motion activity) under different environment temperature conditions.

\section{ACKNOWLEDGEMENTS}

The authors express the gratitude for the valuable advices during the given work conduction to G. A. Finenko, G. I. Abolmasova and Z. A. Romanova, the scientists of the IBSS of NAS of Ukraine; to V. I. Vasilenko and M. I. Silakov, leading engineers of IBSS of NAS of Ukraine, for the help in work with laboratory equipment and making the program of its verification; to D. A. Altukhov, leading engineer for help in sampling the experimental material.

\section{REFERENCES}

[1] Mutlu, E. (1999) Distribution and abundance of ctenophores and their zooplankton food in the Black Sea. II: Mnemiopsis leidyi. Marine Biology, 135, 603-613. doi:10.1007/s002270050661

[2] Gucu, A.C. (2002) Can overfishing be responsible for the successful establishment of Mnemiopsis leidyi in the Black Sea? Estuarine, Coastal and Shelf Science, 54, 439-451.

\section{doi:10.1006/ecss.2000.0657}

[3] Gordina, A.D., Tkach, A.V., Pavlova, E.V. and Ovsyayi, E.I. (2003) The state of ichthyoplanktonic communities in sevastopol bay (the Crimea) between May and September of 1998 and 1999. Journal of Ichthyology, 43, 184-193.

[4] Zaitsev, Yu. and Ozturk, B. (2001) Exotic species in the Aegean, Marmara, Black, Azov and Caspian Seas. Turkish Marine Research Foundation, Istanbul, 265.

[5] Finenko, G.A., Abolmasova, G.I. and Romanova, Z.A. (1995) Ctenophora Mnemiopsis mccradyi nutrition, oxygen consumption and growth, depending on the food concentration. Biologiya Moray, 20, 315-320.

[6] Shushkina, E.A., Musaeva, E.I., Anokhina, L.L. and Lukasheva, T.A. (2000) The role of gelatinous macroplankton jellyfish Aurelia and ctenofores Mnemiopsis and Beroe in the planktonic communities of the Black Sea. Okeanologiya, 40, 859-861.

[7] Zaika, V.E. (2005) Where and how do the Black Sea ctenophore Mnemiopsis leidyi population winters? Morskyi Ekologichnyi Zhurnal, 4, 51-54.

[8] Anninsky, B.E. and Abolmasova, G.I. (2000) Temperature, as a factor of ctenophore Mnemiopsis leidyi metabolism intensity and mass development in the Black Sea. Okeanologiya, 40, 63-69.

[9] Finenko, G.A., Romanova, Z.A. and Abolmasova, G.I. (2000) The new ctenophore-introducer to the Black Seactenophore Beroe ovata brunguiere. Ekologiya Morya, 50, 21-25.

[10] Kovalchuk, L.A., Chashchin, A.K. and Borovskaya, R.V. (1996) Statistical analysis of the association between mnemiopsys concentration and Black Sea surface layer temperature, obtained with ISZ. Trudy Yuzhnogo NauchnoIssledovatelskogo Instituta Morskogo Rybnogo Khozyaistva i Okeanografii, 42, 177-183.

[11] Vereshchaka, A.L. (2002) Peculiarities of the of the microscale distribution of the jelly-body microplankton in the Black Sea near the Gelendzhik coast. Okeanologiya, 42, 91-97.

[12] Tokarev, Yu.N., Mashukova, O.V. and Vasilenko, V.I. (2008) The bioluminescence of the Black-Seas ctenophores-aliens Mnemiopsis leidyi and Beroe ovata under mechanical and chemical stimulation. Ekologiya Morya, 76, 61-65.

[13] Lapota, D. (2012) Bioluminescence-Recent advances in oceanic measurements and laboratory applications. InTech Janeza Trdine, 9, 190.

[14] Vostokov, S.V., Arashkevich, E.G., Dritz, A.V. and Lukashev, Y.F. (2001) Ecological and physiological characteristics of the ctenophore beroe ovata in the coastal waters of the Black Sea: Quantity, biomass, size distribution, hunting behavior, feeding and metabolism. Okeanologiya, 41, 109-115.

[15] Shimomura, O. (2006) Bioluminescence: Chemical princples and methods. World Scientific, 470.

[16] Haddock, S.H.D., Moline, M.A. and Case, J.F. (2010) Bioluminescence in the sea. Annual Review of Marine Science, 2, 443-493. 